\title{
The Application of Switching Control to Boiler-Turbine Coordination in Marine Steam Power Plant
}

\author{
Peng Wang ${ }^{\mathrm{a}}$, Hao Meng ${ }^{\mathrm{a}}$, Jun Liu ${ }^{\mathrm{b}}$, Jiao $\mathrm{Liu}^{\mathrm{c}}{ }^{\mathrm{c},}, \mathrm{Jiajia}_{\mathrm{Li}}^{\mathrm{c}}$ and Jinfu $\mathrm{Liu}^{\mathrm{c}}$ \\ ${ }^{\mathrm{a}}$ The College of Automation, Harbin Engineering University, Harbin, Heilongjiang Province 150001; ${ }^{b}$ Harbin Marine \\ Boiler and Turbine Research Institute, Harbin, Heilongjiang Province 150001; ' School of Energy Science and Engi- \\ neering, Harbin, Heilongjiang Province 150001
}

\begin{abstract}
In the marine steam power plant, the main boiler has the small size and the little heat capacity. However, marine ship requires high maneuverability, when it is running, the loads varied frequently, and the varying range is big, and this will cause the boiler security problem, such as over-pressure or under-voltage. The marine steam power plant boilerturbine coordinated control strategy is to solve the contradiction between the mobility and safety, which is caused by the host load changes quickly and boiler energy supply changes slowly. The traditional boiler following turbine, turbine following boiler or DEB (Direct Energy Balance) can't solve this problem. This paper introduces the multi-objective adjustment / protected thought and proposes boiler-turbine coordination switching based on switching. Based on this switching strategy, we analyze the stability of the system. Finally, we validate the correctness of the strategy by simulation calculation.
\end{abstract}

Keywords: Boiler-turbine coordination, marine steam power plant, multi-objective control, switching control.

\section{INTRODUCTION}

Mobility is one of the main indicators of marine ship tactical performance, which determines its battle and survival capability. Power plant is the heart of the marine ship, whose performance affects the mobility directly. When large marine steam power plant is running, the load changes frequently, and the range is large. At this point, in the process of condition transformation, the plant unit is required to have shorter transition time, no black/white smoke, no over-pressure / under-voltage or other failures. But when the main engine works in this way, the main boiler will suffer impact load. Marine steam power plant generally has no bypass system, which means the main boiler need to coordinate and control all load changes of the main engine. By the restriction of environment, marine main boiler is smaller than stationary boiler in volume and heat capacity. If the coordinated control system is not suitable, the main boiler is hard to meet the requirements of high frequency and large amplitude load changes, which will cause over-pressure and low-voltage problems and influence the safety of equipment. The main problem for the boiler-turbine coordinated control strategy of marine steam power plant is how to solve the contradiction between the mobility and security of power device properly, which is caused by the different change speed of main engine and boiler.

At present, there are few researches on this issue, but we can adopt the thermal power unit coordination control algorithm as their power device are similar. The traditional boiler-turbine coordinated control can be divided into two parts: boiler follows turbine coordinated control and turbine follows boiler coordinated control. Boiler following turbine coordinated control: boiler's fuel supply the required power; the inlet valve of steam turbine adjusts the main steam pressure; this is only suitable for the condition that the unit plant supports basic load. Turbine following boiler coordinated control: the turbine adjusts the load, and the boiler adjusts the main inlet pressure. In this way, we can make full use of the boiler heat storage, so that the unit plant can track the changes quickly in the external load. However, in this way, the main steam pressure will have a greater volatility in the meantime, which will affect the safety and stable operation of the boiler $[1,2]$. Both of the two control systems have some problems. In order to improve the performance of the traditional control system, a feed-forward loop is set to balance the energy supply and demand in the boiler-marine coordinated control system. According to the different relationship between energy supply and demand, the unit plant coordinated control algorithm can be divided into IEB (indirect energy balance) coordinated control and DEB (direct energy balance) coordinated control. The IEB coordinated control system chooses the throttle pressure PT as a characteristic parameter to weigh the energy balance between boiler's output and turbine's input. These characteristic parameters are used to maintain the energy balance of the whole unit plant. Generally, the main controller of turbine and boiler is PID.DEB coordinated control system is the most widely used system. Actually, it is a gain scheduling control, which can eliminate the steady-state gain changes of the unit's control objects with load in the coordinated control system. This system can improve performances of the unit plant under different loads. But the control effect will become worse when the load varies in large range [3]. 
Of all the intelligent method applied to the boiler-turbine coordinated control, fuzzy control, neural network, and genetic algorithm are the most widely used methods [4-10]. The application of intelligent method optimizes the overall performance of the system, and improves its robustness. But there are still many problems when it is used to engineering practice. On the contrary, the traditional boiler-turbine coordinated control has been widely used. But the traditional method cannot meet the requirements of marine steam power plant on mobility and safety.

In this paper, we propose a boiler-turbine coordinated control method of marine steam power plant based on switching law. This method can realize the control of regulation and protection for multiple targets. And then simulate different working conditions by using the Min/Max switching rules. The simulation results show that this method can coordinate the mobility and safety of marine steam power plant well.

\section{APPLICABILITY EVALUATION OF DEB IN THE COORDINATION CONTROL OF MARINE STEAM POWER PLANT}

DEB (Direct Energy Balance) is a widely used method of boiler-turbine coordinated control in power plant at present. As shown in Fig. (1), DEB was first proposed by Leeds \& Northup Co in 1995. With the development and improvement of its application, the DEB system can not only ensure the energy balance of boiler and turbine, but also coordinate the whole key control loop. The DEB system can work from normal operating mode to abnormal operating conditions and starting and stopping conditions. DEB has become a basic and core content to achieve the automation of unit plant at present. This method adopts the energy balance signal $\left(p_{S} \times \frac{p_{1}}{p_{T}}\right)$ as load feed-forward commands of boiler side, and takes heat signal $\left(p_{1}+C_{B} \frac{d p_{d}}{d t}\right)$ as its feedback. As it controls the boiler's input according to the energy demands of turbine, the boiler's energy storage can be used fully and the system has good load adaptability.

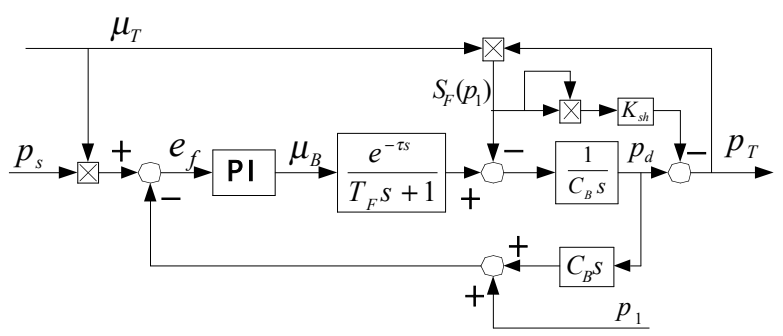

Fig. (1). Principle block diagram of DEB.

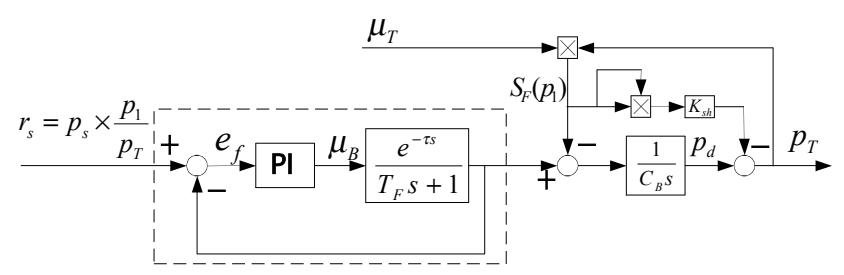

Fig. (2). Principle block diagram of DEB coordinated control system.
But there are some problems in the application of DEB in marine steam power plant. The main problem is that the response speed of DEB system is slow and cannot meet the requirements of the ship's maneuverability. Transform the equivalent block diagram of the DEB system as what has shown in Fig. (2). As the direct energy balance signal of DEB system is given, and the heat signal is its feedback, the boiler furnace wall cooling is chosen as the closed-loop control object of main boiler adjuster, while the steam manifold and super heater are outside the loop.

The nonlinearity of boiler is mainly concentrated in manifold and super heater. In other words, the main nonlinear is placed outside the closed-loop regulation in DEB system and the nonlinearity inside the loop is very weak. Because of the small perturbation of the parameters caused by nonlinearity, the DEB system has a good robustness to the change of the dynamic characteristics of the object.

But on the other hand, as the main energy storage and storage quality of boiler are concentrated on steam manifold and over-heaters (the main inertia and delay link is also put outside the closed-loop), the respond speed of DEB system under boiler's internal disturbance is very slow. To the ground station, it requires high working stability, but the standards for mobility is not strict. As the unit load vary range is small, this issue is not a disadvantage but becomes an important reason for the success of DEB system in ground station.

However, to marine steam power plant, the requirements of mobility is very high. At the same time, the variation range of unit working conditions is much greater than that of ground stations. Thus, it is hard to meet the requirements of safety and mobility at the same time when the working condition varies widely for the boiler-turbine coordinated control scheme based on DEB. In a word, DEB coordination control system cannot meet the requirements of application on ships.

\section{COORDINATED CONTROL METHOD FOR MA- RINE STEAM POWER PLANT BASED ON SWITCH- ING LAW}

\subsection{The Thought of Adjusting/Protecting Multiple Ob- ject Control}

The task of boiler-turbine coordinated control system of marine steam power plant is to ensure coordinated operation of main boiler and engine under the precondition of meeting the demand of load. At the same time, the system needs to respond the load requirement quickly and maintain the stability of main operation parameters. The basic task is to improve the response speed of the unit's rotation speed under the precondition of ensuring the safe operation of the unit.

When the marine steam power plant runs, the main turbine often stops directly and quickly. Sometimes it stops from the maximum speed and sometimes it jumps from closing to a high speed. This operation mode makes the boiler endure impact load. As there is no by-pass system in marine power plant, the main boiler has to control all load changes of the turbine. 


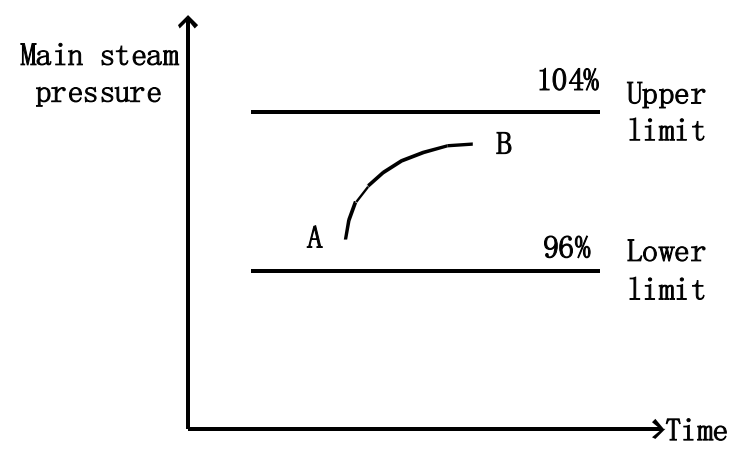

Fig. (3). Safe operation area.

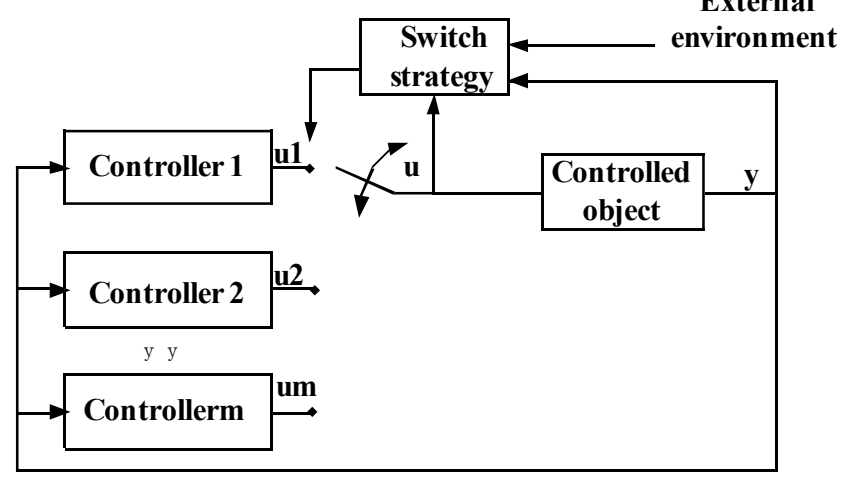

Fig. (4). Architecture of multi-controllers.

So the pressure of steam manifold in main boiler is easy to be higher or lower than the safety limit. As what has shown in Fig. (3), it is safe when the pressure is in the upper and lower bounds, such as the process of A-B. From the above analysis, the current control method cannot realize rapid response requirements and security of main steam pressure in the meantime. To solve this problem, a solution existing now is to bring in feed-forward control technology nonlinear elements and cross link. However, when the working conditions change in a large range, the control effect is not obvious. There is a hydraulic protection systems in marine steam power plant---when the compression system pressure exceeds the set value, it can open automatically and discharge redundant medium to the atmosphere. In this way, pressure vessels and piping systems can work safely and accidents can be avoided. And the system will shut down automatically when the system pressure back down to or slightly lower than the working pressure. However, this is just a protection method. When the pressure is greater than the given pressure, the valve will open and the other state parameters in system maybe uncontrollable.

Both of the two control methods mentioned above design the coordinated control system just on the base of protection, not concerning about the concept of adjustment. When considering security and fast respond speed at the same time, the circuit design will be under strong constraint conditions. As a result, we have to use conservative setting value and sacrifice the fast respond of normal operation to ensure the safety under special working conditions.

In this paper, we propose an idea of regulating and protecting multiple objects: divide the indexes of safety and rapid response into regulation and protection or other control loops as required, then design separately. When the marine steam power plant works in normal conditions, put it into normal control loop to ensure the performance requirements; while the working conditions approach to security border, switch to the protection control circuit to ensure the safety requirements. Through switching the controllers, the contradiction between the rapid response and safety can be solved. From the view of control, this is an issue of multiple loop control, as shown in Fig. (4). We set different parameters to control and protect the target. Establish different parameters regulation / protection control model, and constitute different control loops. Through switching these controllers, the contradiction between fast respond and safety can be solved. Essentially, the multiple control systems is a control problem of the switched system. According to the structure of marine steam power plant, the control structure is designed as shown in Fig. (5).

\subsection{Coordinated Control Scheme Based on Switching Law}

In this paper, we adopt the coordinated control system scheme based on boiler following turbine, and introduce the design of pressure protection circuit. In this way, the safety of unit plant can be guaranteed when the load in marine steam power plant changes greatly.

Compared with turbine, the boiler system's dynamic response is slower and the delay time is larger. Thus, the feedforward signal is introduced to the boiler main control system to improve the adaptability of load and reduce the devia-

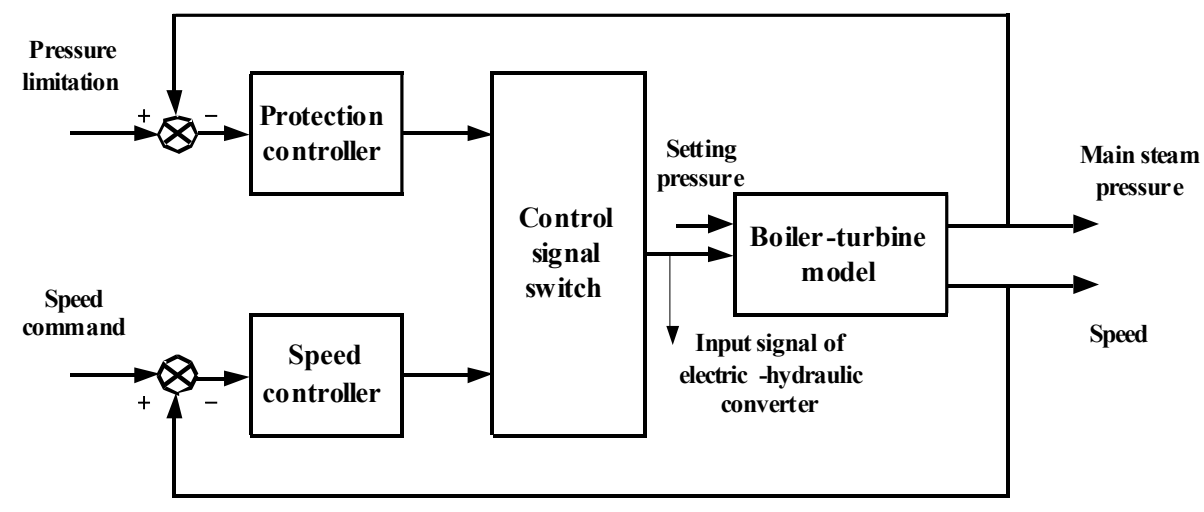

Fig. (5). Control structure of marine steam power plant. 


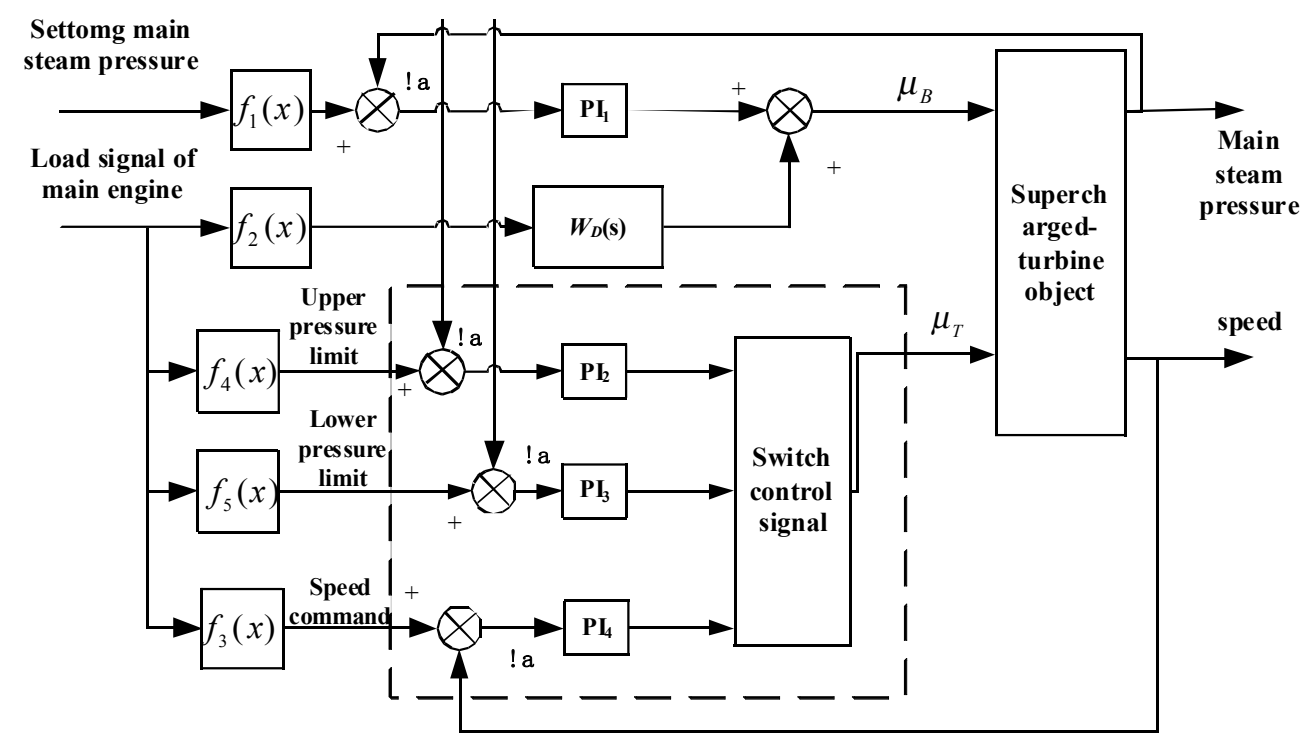

Fig. (6). Principle block diagram of marine steam power plant coordinated control system.

tion of dynamic pressure. In this way, the boiler and turbine can work and coordinate better.

Based on boiler following turbine, this coordinated control scheme with rotating speed feed-forward and multiple loop switching works as what has shown in Fig. (6).

In fact, the telegraph signals on behalf of the marine load is the signal of ship's speed given by cabins. The signal is divided into two parts, one part is chosen as rotating given speed of marine adjustment system through the function $f_{3}(x)$; through the transformation of polygonal function $f_{2}(x)$, the other part is transferred into a signal increase or decrease in accordance with marine load. The second part of signal gets into the adjustment loop of main steam pressure after feed-forward WD(s), and outputs as the compensation signal of PI operation control process. It composes of the boiler's main control signal $\mu_{B}$, and makes up of feedforward and feedback control system with the combustion control system.

When the load of main turbine increases according to the change signal given by the telegraph, the output signal of polygonal function $f_{2}(x)$ increases as well. After WD(s) process, it outputs a positive pulse, which will add to the output signal of main steam adjuster controlled by PI. In this way, the output signal of adjuster will increase. And after the combustion control system, the amount of air and fuel supplied to the boiler will increase as well, to fit the increasing load of turbine. It should be noticed that the feed-forward signal works in advance. It means that the amount of air and fuel the boiler supply will increase before the regulated pressure of main steam drops, to make the dynamic deviations of main steam pressure decrease.

On the contrast, when the load of turbine is required to decrease, the output signal of polygonal function decreases. After WD(s) process, it outputs a negative pulse, which will add to the output signal of main steam adjuster controlled by
PI. The signal of the adjuster outputs decreases. After the combustion control system, the amount of air and fuel supplied to the boiler will decrease to fit the turbine's low load requirement.

When the telegraph signal does not change, the WD (s) output signal is zero. In other words, the feed-forward signal is to no effect, and that's what the system need.

\subsection{Selection of Coordination and Switching Law for the Boiler and Turbine}

We can adopt the switching law of Min/Max to switch the control signals, which is easy to implement.

a. There is clear boundaries and no overlap in the division of process or interval to the switching objects. The switching mode is convenient for the analysis of each sub controller, and the interpretation of the control process is good;

b. When the object model is changed greatly, the model of each controlled sub controller can be adjusted separately.

The principle diagram of the marine steam power plant regulator / protection controller is shown in Fig. (7). And the switching rule is composed of the Min/Max module. To ensure that the boiler is not over-pressure, when the load of turbine is decreasing, always choose larger degree of turbine valve as control signal to select the output of selection blocks. On the contrast, when the load of turbine is increasing, always choose smaller opening of turbine valve. The closing speed of hydraulic actuator will be slower than adjustment controllers in this way. It means that choosing the smaller power change rate as the output signal of selection controller when switching.

\subsection{Analysis of the Stability of Multiple Objects Adjust- ment/Protection to Boiler-Turbine Coordination and Control Scheme}

Essentially, this kind of coordination/protection control system design is a constrained switched control problem of 


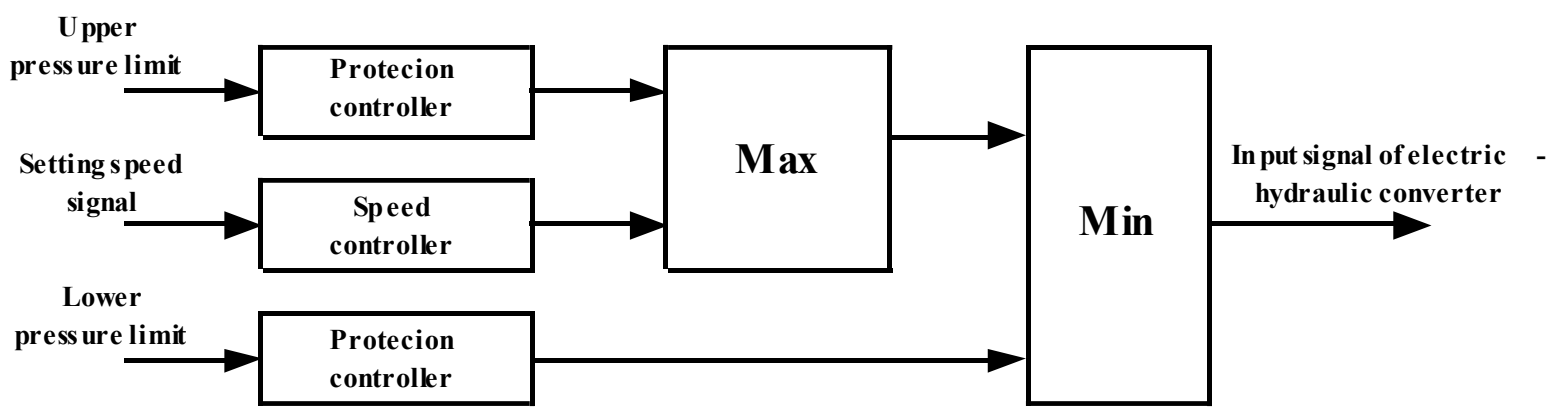

Fig. (7). Principle block diagram of adjustment/protected controller.

multiple models and loops: get the design constraint according to the target controlled by different parameters and the target protected by security boundary, establish the parameter control model and security protection model of marine steam power plant separately. Design these parameter control loop and protection control loop, and change the control mode according to the operation requirement. Through switching these relatively simple controllers, the problems existed in the using of single controller.

This kind of system needs multiple modes to describe its dynamic behavior. Because of the coexistence and interaction of continuous dynamic and discrete switching signals, the dynamic behavior is very complex. Thus, it is very important to design an approximate switching laws (switch signals and regulations) to make sure that each sub control loop stays in a stable state in the process of loop switching. Due to the introduction of discrete state and decision variables in switched systems, the continuous dynamics of system is no longer a set of nonlinear differential or difference equations. With the change of discrete state, the continuity of system jumps, which makes the traditional definition and judging method of stability is no longer applicable to the switching system. Even though the simple linear switching system may become complex. The theory of Switched Control is helpful to analyze and design these problems.

Stability is the basic requirement of control system. Physics suggests that the so-called stability requires the control system to ensure the certain working conditions. In this respect, the main method and content is Lyapunov function and its extension forms, including the construction of arbitrary switching common Lyapunov function, design the use of multiple Lyapunov functions for switching law, method of average residence time and so on. There are also many research results about other basic properties, such as controllability, and so on.

The most important result of switching control theory is the arbitrary switching construction method of common Lyapunov function, multiple Lyapunov function, and the designation of average residence time. It is proved that all subsystems have the common Lyapunov function is the necessary and sufficient condition of the asymptotic stability to switching systems in arbitrary switching conditions. In other words, to a switching system $\dot{x}=f_{i}(x)$, a group of smooth real-valued functions is called Lyapunov function. If it meets these conditions: a. If $V_{i}(x)$ is positive in a neighborhood of origin $\mathrm{B}(0, \mathrm{~h}) \stackrel{\Delta}{=}\left\{\mathrm{x} \in \mathrm{R}^{\mathrm{n}} \mid\|\mathrm{x}\| \leq \mathrm{h}, \mathrm{h}>0\right\}$, and $V_{i}(x)=0 ;$

b. To all arbitrary switching sequence $\sigma\left(\mathrm{x}_{0}\right), \mathrm{x}_{0} \in \mathrm{B}(0, \mathrm{~h})$, which is produced by switching strategy $s$, the inequality $\dot{\mathrm{V}}_{\mathrm{i}}(\mathrm{x})=\frac{\partial \mathrm{V}_{\mathrm{i}}(\mathrm{x})}{\partial \mathrm{x}} \mathrm{f}_{\mathrm{i}}(\mathrm{x}) \leq 0$ is satisfied;

c. When $\|x\| \rightarrow \infty, V_{i}(x) \rightarrow \infty$, of which $t_{k_{1}}, t_{k_{2}}$ is the switching time, and $i_{k_{1}}=i_{k_{2}}, k_{2}>k_{1}$.

Then the switching system is globally asymptotically stable.

In this paper, the $\min / \max$ switching law which is adopted in the multiple adjustment/protection coordinated control scheme of large ship's steam power plant can ensure all switching process is continuous. Generally speaking, although there is no strict mathematical proof, a large number of engineering practice shows that the continuous switching system is more easier to ensure the stability of the existence of common Lyapunov functions.

\section{SIMULATION RESULTS}

As the following boiler-marine coordinated control method of steam power plant based on switching law, we adopt the method of boiler following main engineer, and introduce pressure protection loop to simulate and analyze. And compare the control effect of the coordination methods with and without pressure protection through analyzing the simulation results. The simulation results are shown in Table $\mathbf{1}$, in which the highest main steam pressure of condition 1 and 3 are both $5.6 \mathrm{Mpa}$. Thus, the deceleration process from condition 1 to 2 can simulate the most severe variable condition of pressure control and protection. The simulation results are shown from Figs. (8-13).

From the simulation results, it is easy to see that the boiler-turbine coordinated control method of steam power plant based on switching law has an obvious protective effect. The running line runs along with the security border. The worse the condition is, the better the effect becomes. At the same time, the speed of propeller can decrease quickly. However, under the bad condition such as from condition 1 to 3 , the propeller responds slowly. This is due to the fact that the upper limit value of pressure is low and the boiler's 
Table 1. Simulation conditions.

\begin{tabular}{|c|c|c|c|}
\hline Conditions & $\mathbf{1}$ & $\mathbf{2}$ & $\mathbf{3}$ \\
\hline \hline Speed r/min & 297 & 112 & 220 \\
\hline Power kw & 36000 & 1737.5 & 21286 \\
\hline Main steam pressure MPa & 5.6 & 1.8 & 5.6 \\
\hline Upper pressure & & 1.02 & \\
\hline
\end{tabular}

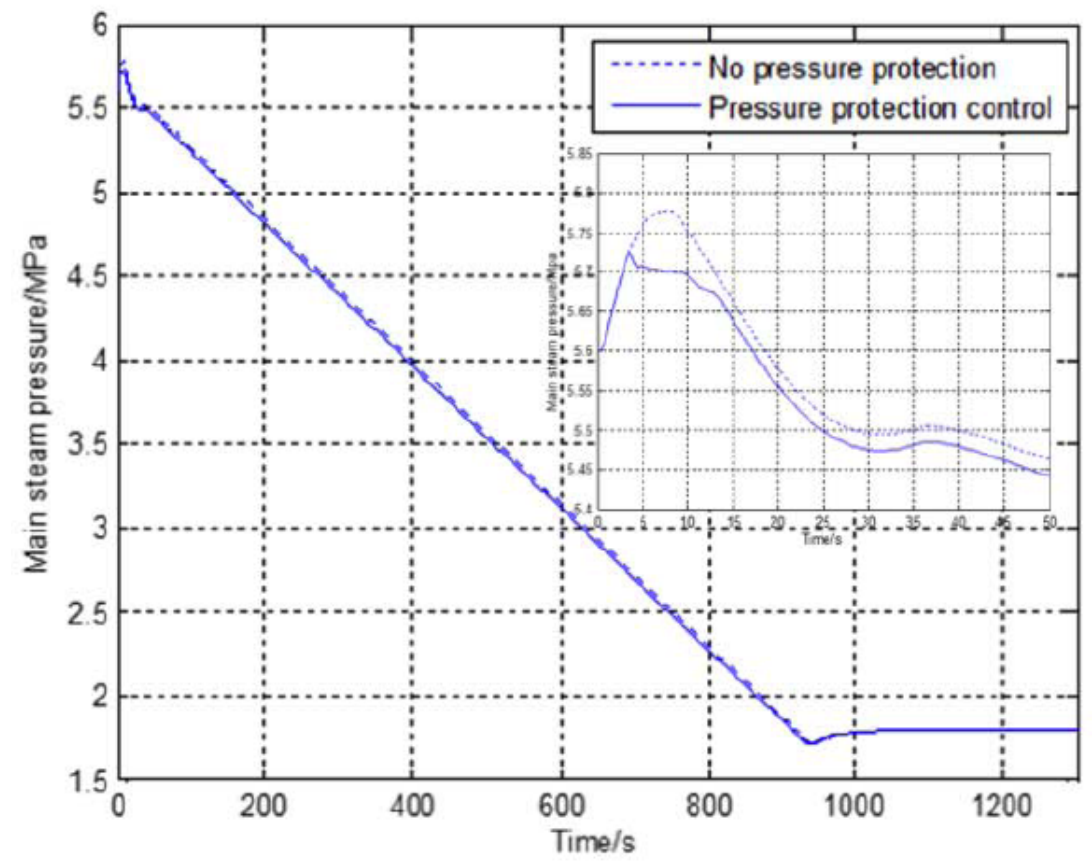

Fig. (8). Output of main steam pressure from working condition 1 to 2 .

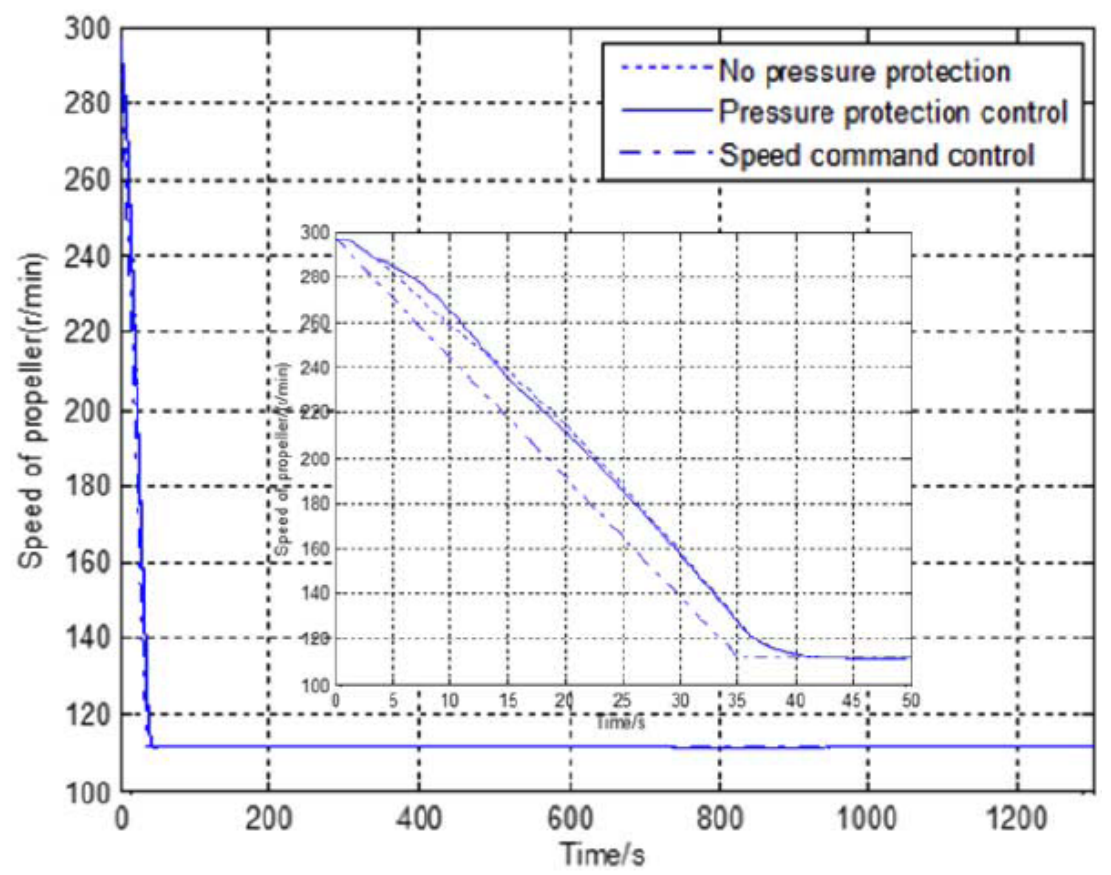

Fig. (9). Output of propeller speed from working condition 1 to 2 . 


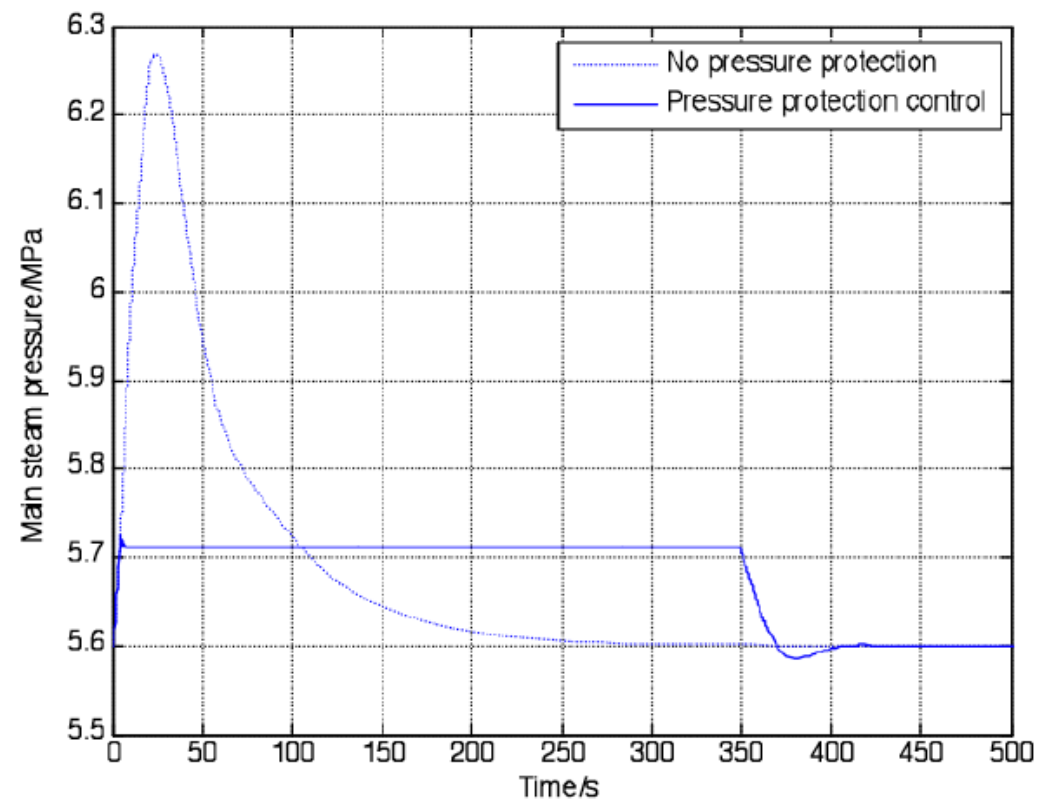

Fig. (10). Output of main steam pressure from working condition 1 to 3 .

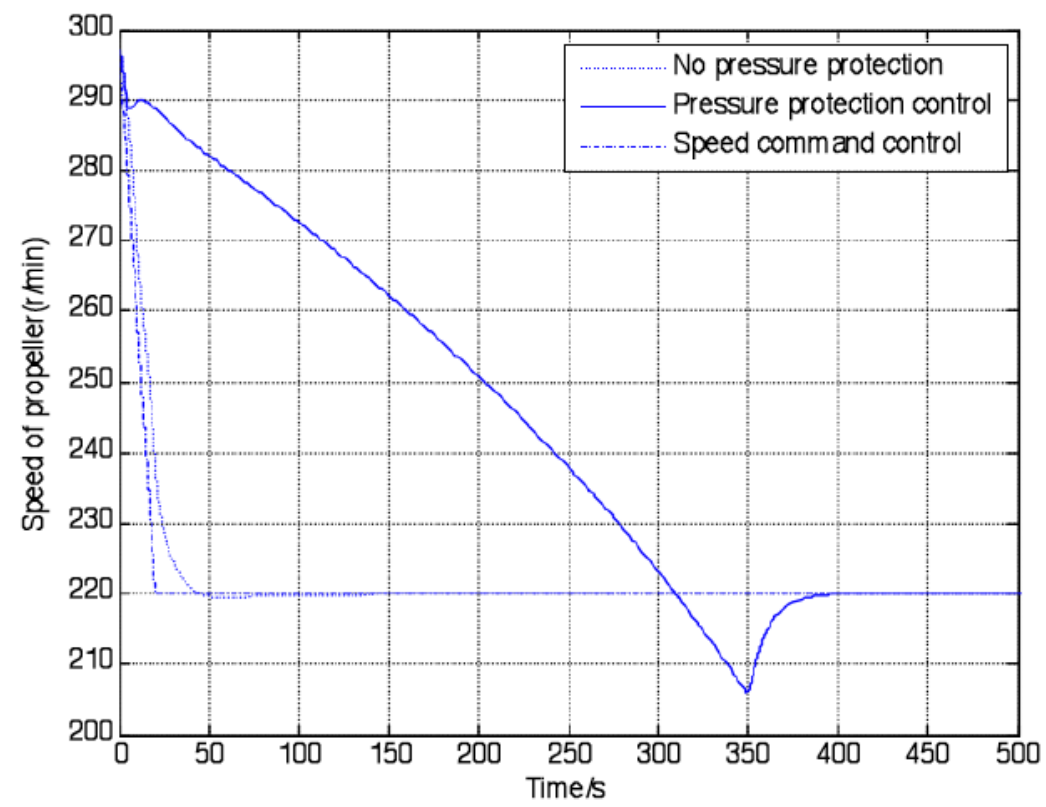

Fig. (11). Output of propeller speed from working condition 1 to 3 .

adjustment speed of pressure is slow through fuel. These two factor cause a long transition time of final speed. If the pressure limit is raised to 1.04 , the response speed of the propeller is obviously accelerated, as Figs. (12) and (13). Totally, the boiler-turbine coordinated and control method for a marine steam power plant based on switching law can solve the contradiction between safety and rapidity.

\section{CONCLUSION}

There are two kinds of traditional boiler-turbine coordinated control systems. One is boiler follows the turbine and the other is turbine follows the boiler. The first one can satisfy the variable load requirement of power network rapidly, but the pressure fluctuates a lot. The second control method causes little pressure fluctuation, but the thermal inertia of boiler is big, and the load adaptability is poor. Obviously, both of these two control systems cannot meet the requirements of maneuverability and safety for marine steam power plant.

For present thermal power units, feed-forward loop is set to improve the performances of traditional control system in the boiler-turbine coordinated control system. The function of the feed-forward loop is balance the relationship between the energy supply and demand in the boiler-turbine system. The most widely used method is DEB coordinated control system, which makes full use of boiler's energy storage and has better load adaptability. But its response speed cannot meet the mobility requirement of marine. 


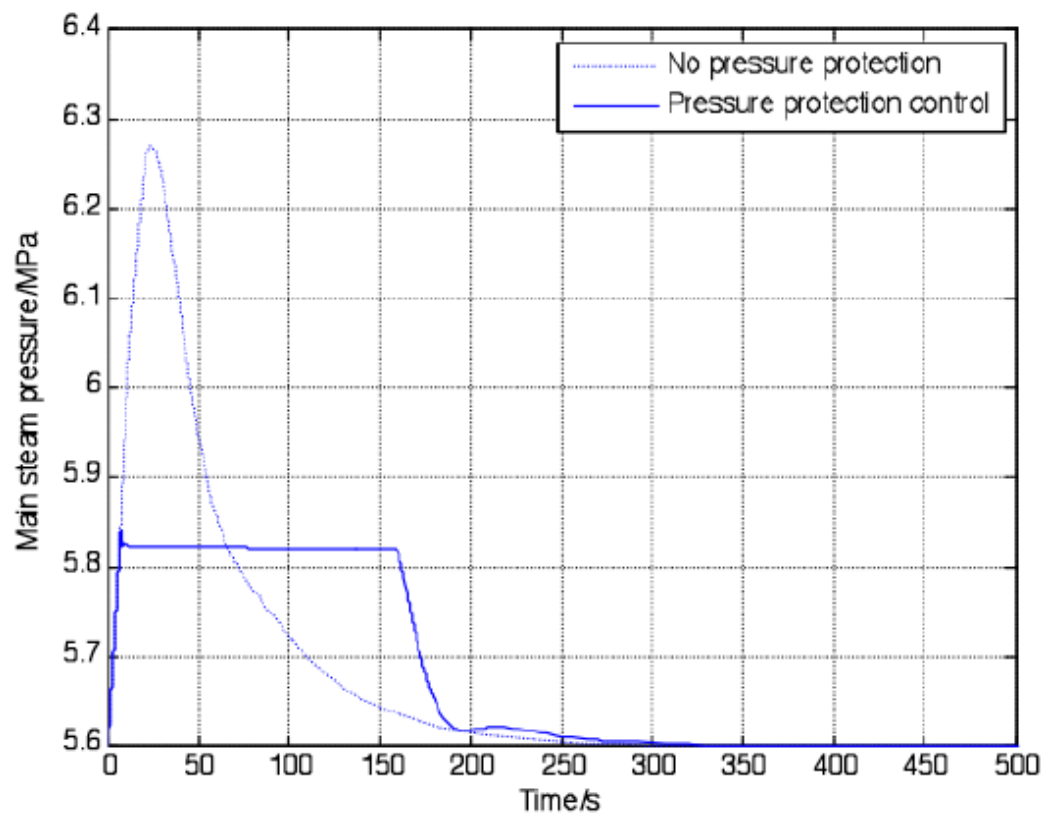

Fig. (12). Output of main steam pressure from working condition 1 to 3 .

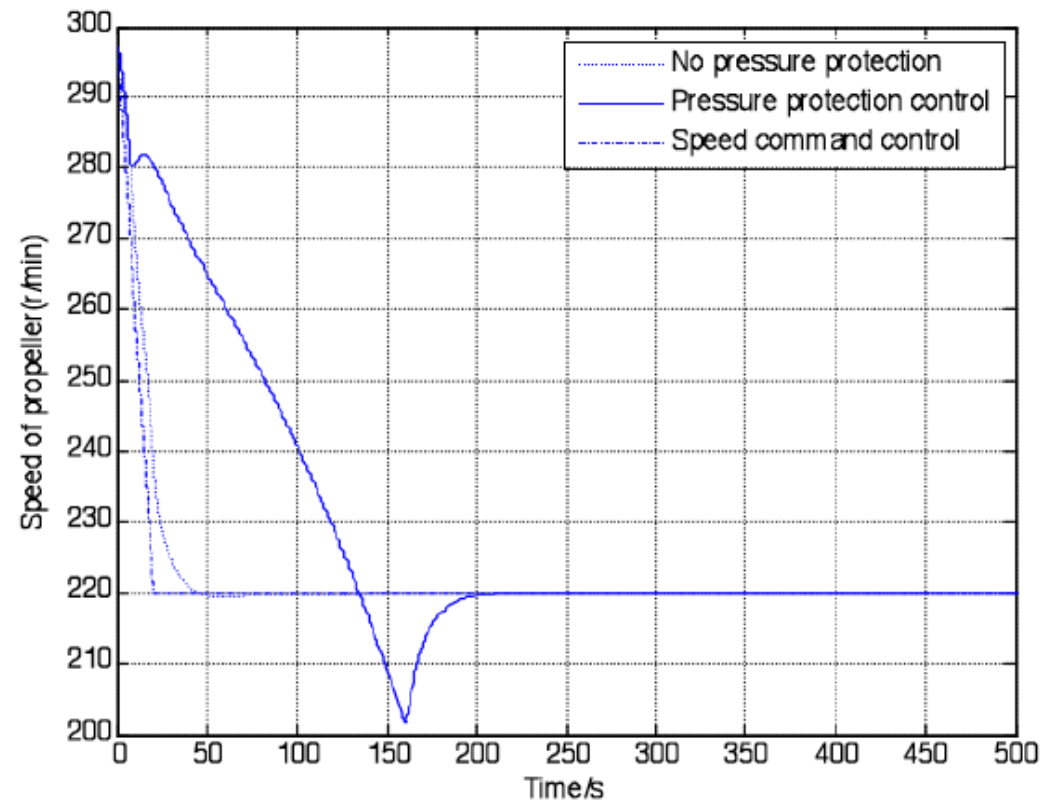

Fig. (13). Output of propeller speed from working condition 1 to 3.

To solve these problems, in this paper, we introduce multi-objective adjustment/protection thought, and on this basis, propose a boiler-turbine coordinated control scheme based on switching rules. When the marine steam power plant runs normally, choose the normal control loop to ensure its performance requirements; while runs near security boundary, switch to the protect and control loop to ensure the security requirements of system. Choose the Min/Max switching rules and analyze the simulation results on variable conditions, we found that on the security aspect, the response curve of main steam almost runs following the security border. While on the rapidity aspect, the propeller's response speed is ideal to some degree. But on bad conditions, the propeller's speed still needs to be strengthened.
Totally, this method can satisfy the requirements of mobility and security for marine steam power plant.

\section{CONFLICT OF INTEREST}

The authors confirm that this article content has no conflict of interest.

\section{ACKNOWLEDGEMENTS}

Declared none.

\section{REFERENCES}

[1] S. Zhang, S. Lu, and H. Liu, "The design of an overall construction scheme of a turbine-boiler coordinated system for a marine steam power plant", Journal of Engineering for Thermal Energy and Power vol. 20, no. 6, pp. 643-646, 2005. 
[2] W. M. Liu, "Research on the control strategies and algorithms of the unit coordinated control system," North China Electric Power University, 2001

[3] D. Yu, Z. Q. Xu, Y. Wen, and Y. H. Li, "A New Understanding of DEB-Gain Scheduling Control," Journal of Engineering for Thermal Energy\& Power, vol. 14, no. 5, pp. 379-381, 1999.

[4] A. Ben-Abdennour, and K. Y. Lee, "Autonomous Control System for Boiler-Turbine Units," IEEE Transaction on Energy Conversion, vol. 11, no. 2, pp. 401-406, 1996.

[5] M. T. H. Beheshti, and M. M. A. Rezaee, "New Hybrid Boiler Master Controller," In: Proceedings of American Control Conference, Anchorage, AK, pp. 2070-2075, 2002.

[6] A. Abdennour, "An intelligent supervisory system for drum type boilers during severe disturbances," Electrical Power and Energy Systems, vol. 22, pp. 381-387, 2002
[7] C. L. M. Harnold, and K. Y. Lee, "Free-model based neural networks for a boiler-turbine plant," Power Engineering Society Winter Meeting, PA, USA, pp. 1140-1144, 2000.

[8] F. A. Alturki, and A. B. Abdennour, "Neuro-fuzzy Control of a steam boiler-turbine unit," In: Proceedings of International Conference on Control Applications, Hawaii, USA, pp. 1050-1055, 1999.

[9] Y. G. Li, J. Shen, and Z. Lv, "Fuzzy Internal Model Control on the Load System of a Thermal Power Unit and its Simulating Study," In: Proceedings of the CSEE, Nanjing, vol. 22, no. 4, pp. 90-93, 2002.

[10] D. W. Kim, H. J. Hwang, and C. S. Hwang, "A design on model following optimal multivariable $\mathrm{H}$ control system using GA," In: Proceedings of the $37^{\text {th }}$ SICE Annual Conference, Chiba, Japan, pp. 975-978, 1998

(C) Wang et al.; Licensee Bentham Open.

This is an open access article licensed under the terms of the (https://creativecommons.org/licenses/by/4.0/legalcode), which permits unrestricted, noncommercial use, distribution and reproduction in any medium, provided the work is properly cited. 